\title{
Research of Inbound Mode for Automobile Parts Logistics Based on the Second Factory of Company H
}

\author{
Depeng Fan \\ Graduate Department, Beijing Wuzi University, Beijing, China
}

Email address:

714169198@qq.com

To cite this article:

Depeng Fan. Research of Inbound Mode for Automobile Parts Logistics Based on the Second Factory of Company H. Journal of Investment and Management. Vol. 5, No. 4, 2016, pp. 34-38. doi: 10.11648/j.jim.20160504.12

Received: July 20, 2016; Accepted: August 1, 2016; Published: August 21, 2016

\begin{abstract}
The article is set in the second factory of company $\mathrm{H}$ and analyzes the present situation and the existence question in the inbound logistics of the factory. A milk-run pickup system is proposed to solve the current predicament of the inbound logistics. The article researches the problems that may happen in milk-run, and then puts forward the corresponding countermeasures to implement smoothly milk-run in the inbound logistics.
\end{abstract}

Keywords: Inbound Logistics, Milk-Run, Third-Party Logistics

\section{Introduction}

With the improvement of people's income and the pursuit of quality of life, automotive industry still has a broad space for development and market opportunities, but also faces many difficulties and challenges. Automobile manufacturing industry must change the traditional mode of production because of the subdivision of the automotive market and the diversified demand of the people, which propose higher requirements to parts logistics, especially the inbound logistics. The inbound logistics is a logistics activity, in which the automobile manufacturing enterprises purchase parts and the suppliers transport the parts to the warehouse on time in accordance with the plan of the automobile manufacturing enterprise [1]. The inbound logistics is in the front of the production logistics and directly affect the production of the following. Therefore, the improvement of the automobile inbound logistics is imperative to meet the higher requirements of the automobile manufacturing enterprises.

\section{Brief Introduction of Milk-Run}

Milk-run mode can be divided into traditional milk-run mode and milk-run mode based on 3PL (Third Party Logistics). Traditional milk-run mode is a mode in which transport vehicles are sent by automobile manufacturing enterprise to suppliers to pick up parts and then return the enterprise [2]. This mode, in which automobile manufacturing enterprises are in the leading position, can improve the loading rate and transportation efficiency to a certain extent, and save the transportation cost. Traditional milk-run mode is suitable for the relatively close supplier whose supply is less, and has the shortcoming include poor cooperation and low utilization rate about information system and so on [3]. Milk-run based on the 3PL is a mode in which according to the predesigned line the $3 \mathrm{PL}$ go to various suppliers to retrieve parts for production in the specified period of time, and then transport these parts to the warehouse or production line side of automobile manufacturing enterprise [4]. This model can improve the vehicle loading rate, avoid empty on return, improve the timeliness and accuracy of parts supply, reduce the components inventory of automobile manufacturing enterprise, and ultimately reduce cost of automobile manufacturing enterprise and suppliers [5].

\subsection{The Advantages of Milk-Run}

Milk-run is an optimal way to pick up, it can not only reduce the inventory of the automobile manufacturing enterprise and the risk of stop line due to out of stock, but also can reduce the cost of the supply chain. In a word, milk-run has advantages as follow: 


\subsubsection{To improve the Loading Rate and Efficiency of Transport Vehicles}

Milk-run shorten the total transport distance of parts in the same amount of daily production, improve the efficiency of transportation and the loading rate, and reduce the waste of load, therefore, the cost of transportation is reduced [6].

\subsubsection{To Reduce the Cost of Transportation}

Two or more suppliers are focused on one line, the total transportation distance can be reduced in this way. With the continuous improvement of the cycle path, the cost of transportation will continue to reduce.

\subsubsection{Supply of Parts Is Guaranteed}

Automobile manufacturing enterprise, suppliers and third party logistics jointly participate in the process of milk-run, each partner can quickly adjust and solve the trouble when the process of milk-run is in trouble. Automobile manufacturing enterprise can monitor the process of milk-run, so as to reliability of parts could be ensured. At the same time the process of milk-run is operated by the professional 3PL that can ensure the condition of vehicle, the diathesis of drivers and professional requirements, which can make delivery of parts to be safe.

\subsubsection{To Reduce Inventory}

According to the production plan, 3PL sent transport vehicles to pick up parts from each supplier, which is based on the principle of low volume and multi frequency. Frequency and amount of daily pickup are certain, which both ensure the timely supply of parts, but also reduce the warehouse inventory of the third-party logistics and the risk of stop line due to out of stock.

\subsubsection{More Professional}

The third party logistics company which works with the automobile manufacturing enterprise is more professional, the third party not only can use the advantages of scale to provide professional and efficient service, but also guarantee the timelines of delivery. In the process of cooperation with the third party logistics, the automobile manufacturing enterprise could set up an information sharing platform and can implement real-time monitoring of all aspects of the transport by positioning technology, in order to reduce the uncertainty risk and loss to the automobile manufacturing enterprise [7].

\subsection{The Limitations of Milk-Run}

Although milk-run has many advantages, not all enterprises are suitable to use it. Milk-run has its own limitations.

Milk-run is only suitable for the delivery based on the principle of low volume and multi frequency, and has more stringent requirements on the pick-up and delivery time [8]. If the parts do not reach the designated position on time, it will have a certain impact on the production and inventory, even causing stop line due to out of stock.

In milk-run all aspects and complexity of the coordination are high, if coordination is not good, it will be very difficult to obtain satisfactory results, even increasing the risk of stop line.

\section{The Present Situation and Question in the Inbound Logistics of Company $H$}

\subsection{The Present Situation of the Inbound Logistics}

At present, company $\mathrm{H}$ has two factories in Zhengzhou, this article is based on the second factory as an example. The factory has three passenger vehicle which are produced by a same line in the assembly department. In order to meet the market demand, the company plans to achieve flexible production in the future, so the logistics system of the company will be faced with new challenges. There are three kinds of existing the inbound logistics delivery:

(1) Nonlocal suppliers transport parts to the 3PL warehouse, and then the 3PL distribute parts to the assembly department according to the production plan of the factory. This delivery method can easily generate repeated transportation costs, and may cause delivery delays or serious damage [9].

(2) Suppliers around the factory distribute their parts to the assembly department according to the production plan, or sent parts to the 3PL warehouse, and then the 3PL distribute parts to the assembly department.

(3) Parts of Suppliers around the city will be taken by the 3PL and shipped to the 3PL warehouse and then distributed parts to the assembly department.

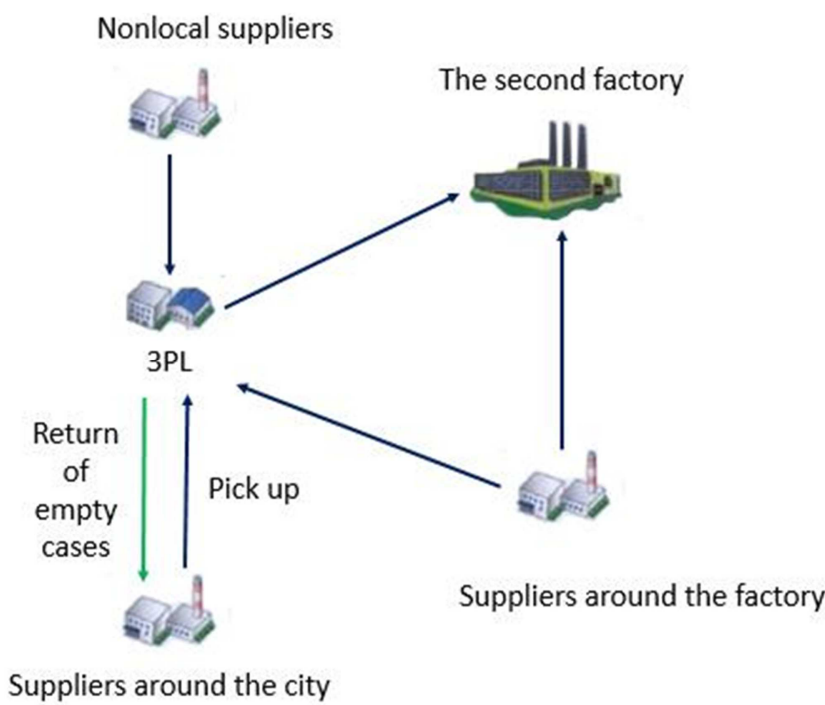

Figure 1. The existing inbound logistics mode of company $H$.

In order to save the cost of transportation, nonlocal suppliers transport a large number of parts to meet the production of 4 days or so for company $\mathrm{H}$, which lead to an increase in storage costs. Although suppliers around the city and factory adapt the supply mode of small batch and multi batch, this mode has the phenomenon of low loading rate, which causes a rise in transportation costs. Therefore, the current inbound logistics mode lead many funds of company 
$\mathrm{H}$ and suppliers to be occupied, and increase the risk of stop line.

\subsection{Problems in the Inbound Logistics}

With the increase of the number of cars, the types and quantity of related supporting parts are growing. Suppliers are mainly responsible for the inbound logistics, but the participation of the factory in this process is very low. Therefore, in the inbound logistics there are some problems as follow:

\subsubsection{High Cost of Inbound Logistics}

Suppliers choose the logistics service provider in the existing supply logistics of company $\mathrm{H}$, and then arrange the logistics service provider to transport parts to the designated warehouse according to the production plan. The price offered by suppliers include the logistics cost that can not be determined whether it is reasonable. In fact suppliers can make additional profit from parts logistics by the way of quoted price.

When automobile manufacturing enterprise requires suppliers to reduce parts quotes in the negotiation, some suppliers only reduce the cost of logistics and will choose low-cost logistics service providers or reduce the quality of parts packaging. There is no mutual cooperation between the suppliers in the same area, which increases the comprehensive cost of the supply chain to a certain extent, but suppliers can improve the logistics efficiency by effective cooperation in the same area, so as to achieve the purpose of reducing the logistics cost.

\subsubsection{Lack of Monitoring in the Logistics Process}

Supplier of company $\mathrm{H}$ is located all over the country, only a few suppliers set up factory around company $\mathrm{H}$, more suppliers entrust logistics service providers or rely on their own fleet to transport parts. With the development expansion, company $\mathrm{H}$ put forward higher requirements for suppliers in these areas, include reaction speed, delivery frequency accuracy of delivery time and the quality of parts. Because suppliers organizing transportation by themselves, logistics process is lack of effective monitoring, once parts have an accident on the way, company $\mathrm{H}$ will face the risk of stopping line except that suppliers use the high mode of transport, such as air transport.

\subsubsection{The Big Pressure of Storage}

In addition to the suppliers around company $\mathrm{H}$ can quickly respond to production, other suppliers store parts in the warehouse of the third party logistics, so that suppliers is highly dependent on the third party logistics warehouse. Some suppliers transport more parts than the order quantity of company $\mathrm{H}$ in order to reduce their cost. In the wake of increase of models, the demand of the 3PL warehouse area and the number of suppliers and parts are also increasing, resulting in the big pressure of storage. At the same time, some scrap parts are still in the warehouse and not back to the suppliers in time and will consume a certain storage area over a long time accumulation, resulting in a waste of storage area.

\section{Project Planning of Milk-Run in Company $\mathbf{H}$}

Learning from the current domestic experience of automobile enterprises, company $\mathrm{H}$ can implement milk-run on some suppliers which supply many parts and are located in a relatively concentrated location to cope with the above problems in the inbound logistics.

\subsection{The Necessity and Feasibility of Milk-Run Implementation in Company $\mathrm{H}$}

In order to solve the problems in the inbound logistics, company $\mathrm{H}$ need to implement milk-run.

(1) The inbound way based on the principle of low volume and multi frequency can reduce the inventory of company $\mathrm{H}$, milk-run can improve the loading rate of transport vehicles and reduce the investment of suppliers in personnel, facilities, and equipment and so on. Now 3PL that is cooperating with company $\mathrm{H}$ is providing the service of pick-up for some suppliers, therefore, 3PL has more experience. Through the daily effective management, the service level of 3PL can be enhanced in order to ensure smooth implementation of milk-run.

(2) By setting the time window in milk-run, parts can be continuous transported to company $\mathrm{H}$, which not only can make use of the advantages human and improve utilization of the warehouse, but also reduce the storage period of parts.

(3) priority implementation area of milk-run can choose Kaifeng parts Industrial Park in which some suppliers are concentrated, suppliers cooperate with $\mathrm{H}$ for a long time, the relationship is relatively stable between them, Besides, these suppliers produce parts of three kind of vehicle and produce more types and quantities of parts for $\mathrm{H}$, which create favorable objective conditions for the implementation of milk-run.

\subsection{The General Idea of Milk-Run for Company $H$}

During milk-run, 3PL arrives at suppliers nearby $\mathrm{H}$ to collect parts and determine the frequency of delivery according to the production plan and production methods of $\mathrm{H}$, 3PL could only pick up once to meet production for parts with less demand. In the planning stage, company $\mathrm{H}$ can consider Kaifeng parts Industrial Park as the first pilot, and then extend milk-run to other suppliers after the success of the pilot. It should be noted the following aspects in milk-run:

(1) $\mathrm{H}$ should lead the implementation of milk-run and make full use of professional advantages of 3PL to ensure smooth progress of milk-run.

(2) According to the production plan, purchasing department sent purchase orders to the supplier, parts are prepared by suppliers within the specified time after the receipt of orders and picked up by 3PL.

(3) According to the current situation, $\mathrm{H}$ should calculates logistics expense of parts with suppliers, control or deal with possible abnormal situation in milk-run and constantly improve the process of milk-run etc. 


\subsection{The Design Principles of Milk-Run}

The milk-run mode of company $\mathrm{H}$ could be designed by the principles as follow:

(1) According to the production plan and the location of supplier, 3PL design a reasonable path to pick up, delivery time, frequency of transport and loading rate, which ensure that parts of suppliers are timely transported to $\mathrm{H}$.

(2) H, suppliers and 3PL must achieve full trust and keep the information sharing each other.

(3) In milk-run, arrival time and departure time of transport vehicle should be strictly obeyed to ensure the normal operation of the production line.

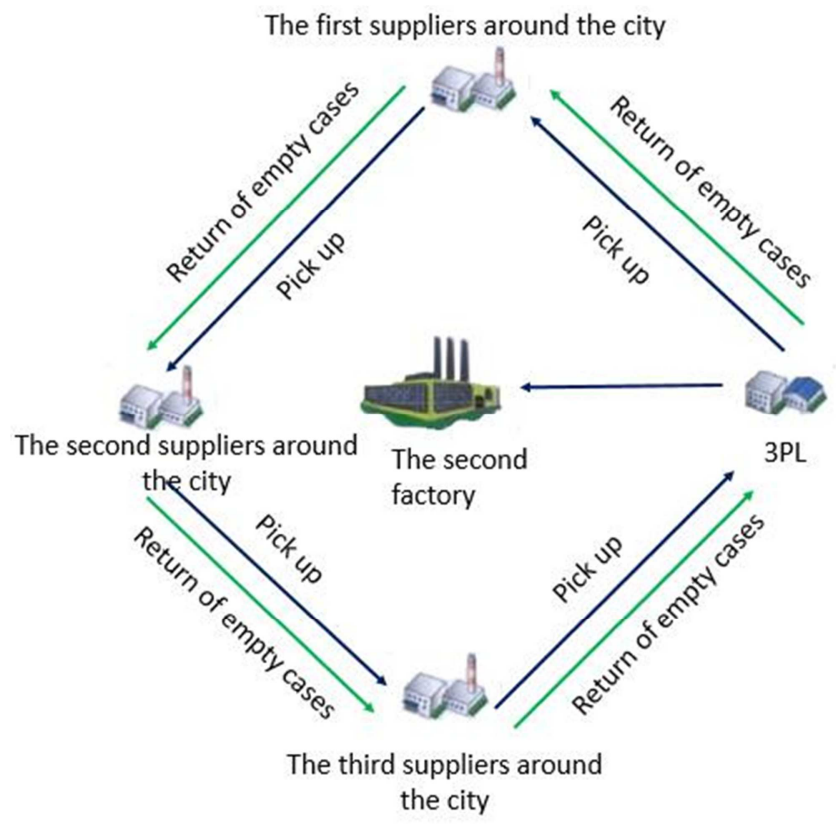

Figure 2. The milk-run supply logistics model.

\section{Considerations and Strategy of Milk-Run Implementation in Company $\mathbf{H}$}

\subsection{Difficulties in the Implementation of Milk-Run}

The implementation of milk-run needs to meet some certain conditions, if the company does not have these conditions, milk-run will meet a lot of difficulties.

\subsubsection{Accuracy of the Production Planning Need to Improve}

After coming out of the painting, bodywork enter the buffer in which 600 bodywork can be accommodated to sort, however, sorting for a long time will cause that some bodywork can not be timely conveyed to the assembly department on schedule, resulting in abnormal changes such as the type, quantity and time of parts.

\subsubsection{Not Cooperation}

For one thing, inventory of 3PL will be reduced, and inventory of suppliers will be increased, which will increase storage cost of suppliers, the pressure of suppliers will be enlarged, because some suppliers also provide parts for other automobile manufacturing enterprise. For another, packaging standard of every supplier may be not unified, for example, specifications of work place tool chests is not same, which will cause that tools between suppliers can not be stacked in the process of delivery and result in the waste of vehicle space. However, the uniform specification of the tools will cause suppliers to buy or make new ones and increase the cost of suppliers.

\subsubsection{Lack of Information Sharing Platform}

Parts Milk-run is based on the information sharing [10]. Company $\mathrm{H}$ requires to formulate accurate production planning at each stage in milk-run, when problems arise in the production or change of plan, company $\mathrm{H}$ should notify suppliers and 3PL to make them respond quickly to changes. But the three parties still rely on the traditional way of communication and lack an effective information sharing platform at present and can not timely share information, which will caused certain difficulties in the implementation of milk-run.

\subsubsection{Parts Quality Is Difficult to Guarantee}

For one thing, parts that suppliers provide for $\mathrm{H}$ can not be guaranteed to be fully qualified, for another, $\mathrm{H}$ can not spare parts without waste in the production process. Once parts have problems, the production and delivery will be affected. The problem will be more complex when it relates to quality responsibility traceability of parts.

\subsection{Countermeasures and Suggestions}

In order to solve the problem mentioned above, some suggestions are put forward.

\subsubsection{To Improve the Accuracy of Production Plan}

The production department planner should make an accurate plan and reduce alterations in production planning. Every department, especially the assembly department, should be responsible for the implementation of the production plan, in order to provide accurate information of parts for the suppliers.

\subsubsection{To Improve the Enthusiasm of Suppliers}

The company should make suppliers participate in milk-run and let them know about the benefits of milk-run. Rectification of work place tool chests must have a gradual process in which company $\mathrm{H}$ must participate.

\subsubsection{To Establish the Information Sharing Platform}

The company should feed back the information of parts to suppliers and 3PL, if there are changes in the production planning, changes are still quickly transferred to suppliers and 3PL, in order to ensure that they have enough time to deal with the changes. The inventory information of suppliers and transportation information of 3PL should also be timely shared to the production management department of company $\mathrm{H}$.

\subsubsection{To Improve the Quality Level of Parts}

Suppliers should improve their level of production technology to ensure the quality of parts, which can also 
reduce their production costs, while suppliers should strictly control the quality of parts. The production department of $\mathrm{H}$ should improve the skills of the operator and reduce the waste of parts in the production process.

\section{Conclusion}

The competition between automobile enterprises is becoming more and more fierce, the demand of people also tends to diversification, each enterprise needs to improve its own logistics model to adapt to the new competition. Milk-run is suitable for parts logistics, and has the advantages of high transport efficiency, fast response and high level of service. By analyzing the problems existing in the inbound logistics of company $\mathrm{H}$, the author think milk-run is suitable to solve the current predicament of the inbound logistics. And then the author put forward the implementation feasibility and necessity, general ideas and design principles of milk-run. However, milk-run is a complex system and needs to carry on the design and plan in many ways. This article do not carry out the thorough discussion and analysis on the concrete construction and design of milk-run, it also needs to conduct a more in-depth study in the future.

\section{References}

[1] Pei Zhichao. Study on vehicle routing problem of Automotive Parts milk-run with Time Windows and Inventory Constrained [D]. Jilin University, 2014.
[2] Lin Chunken, Dong Baoli, Chen Yangchun. Study on Mixed Milk-run Mode for Two-Level Suppliers [J]. Zhejiang Sci-Tech University (Social Sciences), 2014(6): 460-464.

[3] Pan Xiang, Meng Liqing. Analysis of Inbound Mode for Auto Parts Logistics [J]. Logistics Technology, 2014(3): 71-73.

[4] Chen Jingjing. Recycling pickup route planning and optimization for Company X [D]. South China University of Technology, 2014.

[5] Wang Lingyan. Based on the Operation Mode of Automobile Spare Parts Inbound Logistics 3PL and Operation Research [J]. Traffic \& Transportation, 2013(2): 154-156.

[6] Sun Weiqing. Study on A Company Inbound Logistics Management Optimization Based on Milk-run Pickup Mode [J]. Logistics Engineering and Management, 2014(8): 41+70.

[7] Zhou Zhou, Zeng Haiping, Li Bo. Optimization method of parts pick up Logistics in Guangzhou Honda [J]. Logistics \& Material Handling, 2009(10): 66-70.

[8] Chen Jingjing. Inbound logistics planning of automobile enterprises S based on MILKRUN [D]. Zhengzhou University, 2014.

[9] Zhang Yan, Liu Jinxia. Explore Auto Parts Supply Logistics Modes [J]. Logistics \& Sci-Tech, 2014(5): 114-116+119.

[10] Gao Xiaonan. Research on Inbound Logistics Processing Optimization of Automobile Parts and Application [D]. Zhengzhou University, 2014. 